\title{
Aplazia Kutis Konjenita'lı Olguların Değerlendirilmesi ve İzlemi
}

\author{
${ }^{1}$ Tuğba Barsan Kaya, ${ }^{2}$ Neslihan Tekin, ${ }^{2}$ M. Arif Akşit \\ ${ }^{1}$ Eskişehir Osmangazi Üniversitesi Tıp Fakültesi Çocuk Sağlığı ve Hastalıkları Anabilim Dalı, \\ Neonatoloji Bilim Dalı, Eskişehir \\ e-posta: tugbarsan@hotmail.com
}

\begin{abstract}
ÖZET: Aplazia kutis konjenita (AKK) nadir görülen, doğumda izole ya da yaygın alanlarda cilt yokluğu ile karakterize heterojen hastalık grubudur. İnsidansı 1:10 000'dir. Kız ve erkekleri eşit oranda etkiler. Etnik kökene bağlı sıklığında artış tanımlanmamıştır. Sıklıkla tek, küçük (0.5-3 $\mathrm{cm}$ ), skalp yerleşimlidir. Çeşitli sendromlarla birlikteliği olsa da, sıklıkla izole lezyon olarak görülür. Kemik yokluğunun da eşlik ettiği olgularda komplikasyon sıklığında artış olabilir. Burada skalpta, kemik yokluğunun eşlik etmediği aplazia kutis konjenita tanısı alan iki yenidoğan sunulmuştur. Özellikle sendromik bulguları olmayan vakalarda, saçlı deride gözden kaçabilecek bir lezyon olması, eşlik edebilecek kemik defektleri açısından değerlendirmenin önemi vurgulanmıştır.
\end{abstract}

ANAHTAR KELIMELER: Yenidoğan, skalp, cilt defekti, aplazia kutis konjenita

SUMMARY: Aplasia cutis congenita (ACC) is part of a heterogeneous group of disorders which is characterized by the absence of a portion of skin in a localized or widespread area effecting approximately 1 in 10,000 newborns. There is no sex predilection or increase in the frequency depending on ethnic origin. Lesions are mostly seen on the scalp as a solitary, small $(0.5-3 \mathrm{~cm})$ lesions with varying degrees in deepness. Although the association with various syndromes has been defined, it is mostly seen as isolated lesions. If careful examination is not performed and the consequences of the aplasia cutis congenita is not known, underlying bone defects in nonsyndromic cases is unrecognized. Here in we reviewed the diagnosis and management of aplasia cutis congenita with relevant literature. by presenting two newborn cases

KEY WORDS: Newborn, scalp, skin defects, aplasia cutis congenita

\section{Giriş}

Aplasia kutis konjenita (AKK) doğumda cildin, daha nadir olarak da cilt altı dokuların değișen derecelerde yokluğu ile giden bir hastalık grubudur. (1). İlk kez Cordon tarafından 1767 'de iki k1z kardeşte alt ekstremitelerde, Campbell tarafindan 1862'de saçlı deride tanımlamıştır. Adams ve Oliver 1945'de Aplasia cutis'le birlikte distal ekstremite anomalileri olan sendromu yayınlamıştır $(2,3)$. Frieden 1986 'da hastalığı lezyonun karakteri ve eşlik eden malformasyonlara göre 9 grupta sinıflandırmıştır (4). S1klıkla tek ve küçüktür $(0.5-3 \mathrm{~cm})$, \%70'i saçlı deride yerleşimlidir (5). Erken gebelik haftalarında oluşan lezyonlar doğumda atrofik ya da membranöz lezyon olarak görülür. Çoğu vakada ise doğumda fokal ülsere lezyon olarak saptanır. Çeşitli sendromlarla birlikteliği olsa da, sıklıkla izole olarak görülür (6). Hastalığın insidans1 1-3/2000-10000'dir. K1z ve erkekleri eşit oranda etkiler. Etnik kökene bağlı sıklığında artış tanımlanmamıştır. Cilt altında kemik yokluğunun da eşlik ettiği olgularda hemoraji, enfeksiyona bağlı komplikasyon sıklığı artar. $\mathrm{Bu}$ vakalarda cerrahi gerekebilir (6). Burada saçlı deride, kemik yokluğunun eşlik etmediği aplazia kutis konjenita tanısı alan 
iki bebek sunulmuştur. $\mathrm{Bu}$ yazıda ilave anomalisi olmayan aplazia kutis konjenitalı iki bebek sunulmuştur. Aplazia kutis konjenitanın izole olarak da görülebileceği vurgulanmak istenmiştir. Olgu sunumu; 27 yaşındaki annenin 2 . gebeliğinden 2. yaşayan olarak son adet tarihine (SAT) göre 35 hafta, 4 hafta intrauterin gelişme geriliği ile 6-9 Apgar $1590(<5$ p) gram olarak doğdu. Bebeğin fizik muayenesinde periferik siyanozu, burun kanadi solunumu ve posterior parietal alanda saçlı deride keskin sınırlı, izole kırmızı parlak zeminde saçsız, yüzeyi kurutlu alan saptandı (Resim-1). Vücudun diğer bölgelerinde ciltte lezyon yoktu, parmak ekstremite anomalisi saptanmadi. Anneye 30. haftadan itibaren gestasyonel DM ve preeklampsi tanısı ile yatırılarak insulin ve metildopa tedavileri başlandığ 1 öğrenildi. Doğum öncesi çalışılan hepatit, TORCH serolojisinde özellik yoktu. Gebelik süresince veziküler döküntülerle giden enfeksiyon geçirmemişti. Anne baba arasında akrabalık yoktu. Ailede cilt problemleri ya da genetik hastalık tanımlanmadi. Yenidoğan yoğun bakım ünitesinde 1. gün nazal CPAP'da izlendi. Solunum sikıntıs1 gerileyen bebeğin 3. günden itibaren ek oksijen gereksinimi kalmadi. Solunum sıkıntısı düzeldikten sonraki dönemde çalıșılan metabolik, biyokimyasal ve hematolojik parametrelerinde özellik saptanmadi. Kraniyal MR görüntülemesinde beyin parankiminde ve kemikte defekt izlenmedi. İzole cilt defekti olan bebek plastik cerrahi ile konsulte edildi. Yumuşak parafin ile doyurulmuş, $\% 5$ oranında klorheksidin asetat ile pansuman önerildi. Yatış1 süresince pansumanı yapılan bebek 15 . günde yakın poliklinik izlemi ile taburcu edildi.

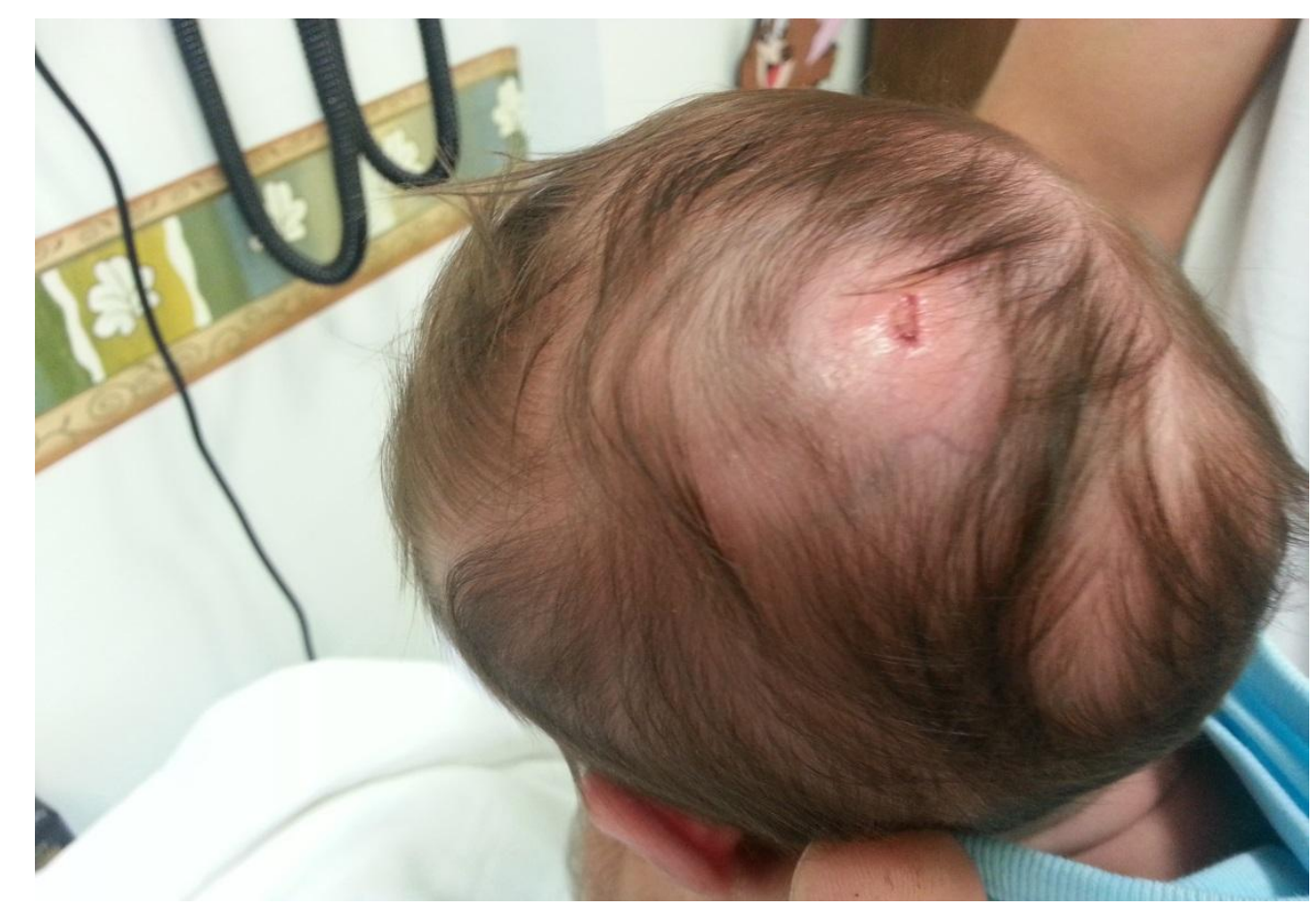

Resim 1. Hastanın saçlı derisindeki cilt defekti 


\section{Olgu}

37 yaşındaki annenin takipli 2 . bulgusu olmayan bebek nörolojik olarak gebeliğinden 2. yaşayan olarak SAT'ne aktif görünümdeydi. Diğer sistem göre 38 hafta 5 günlük $\mathrm{C} / \mathrm{S}$ ile başka bir muayenelerinde özellik saptanmad. sağlik kuruluşunda doğan bebek Annenin prenatal ve perinatal laboratuvar hastanemize saçlı deride cilt yokluğu parametrelerinde özelik yoktu. Hamileliği nedeniyle yönlendirildi. Fizik süresince ilaç kullanmamıştı. Ailede cilt muayenesinde vücut ağırlığı 2650 gr $(5 p)$ hastalığı ya da genetik hastalık öyküsü boy $48 \mathrm{~cm}(10-25 \mathrm{p})$ baş çevresi $34 \mathrm{~cm}$ yoktu. Çekilen kraniyal MR $(10-25 \mathrm{p})$ Sol parietooksipital alanda görüntülemede beyin parankimi normal $2 \times 1.5 \mathrm{~cm}$ boyutunda keskin sinırlı etrafi kemik dokuda defekt izlenmedi. Lezyonlu hiperemik cilt yokluğu mevcuttu. cilt bölgesine yumuşak parafin ile (Resim-2) lezyon zemininde kemik doku doyurulmuş, \%5 oranında klorheksidin palpe ediliyordu. Bebeğin vücudunun asetat ile pansuman yapılarak yakın diğer bölgelerinde cilt yokluğu izlenmedi, poliklinik izlemi ile taburcu edildi. ekstremite anomalisi yoktu. Sendromik

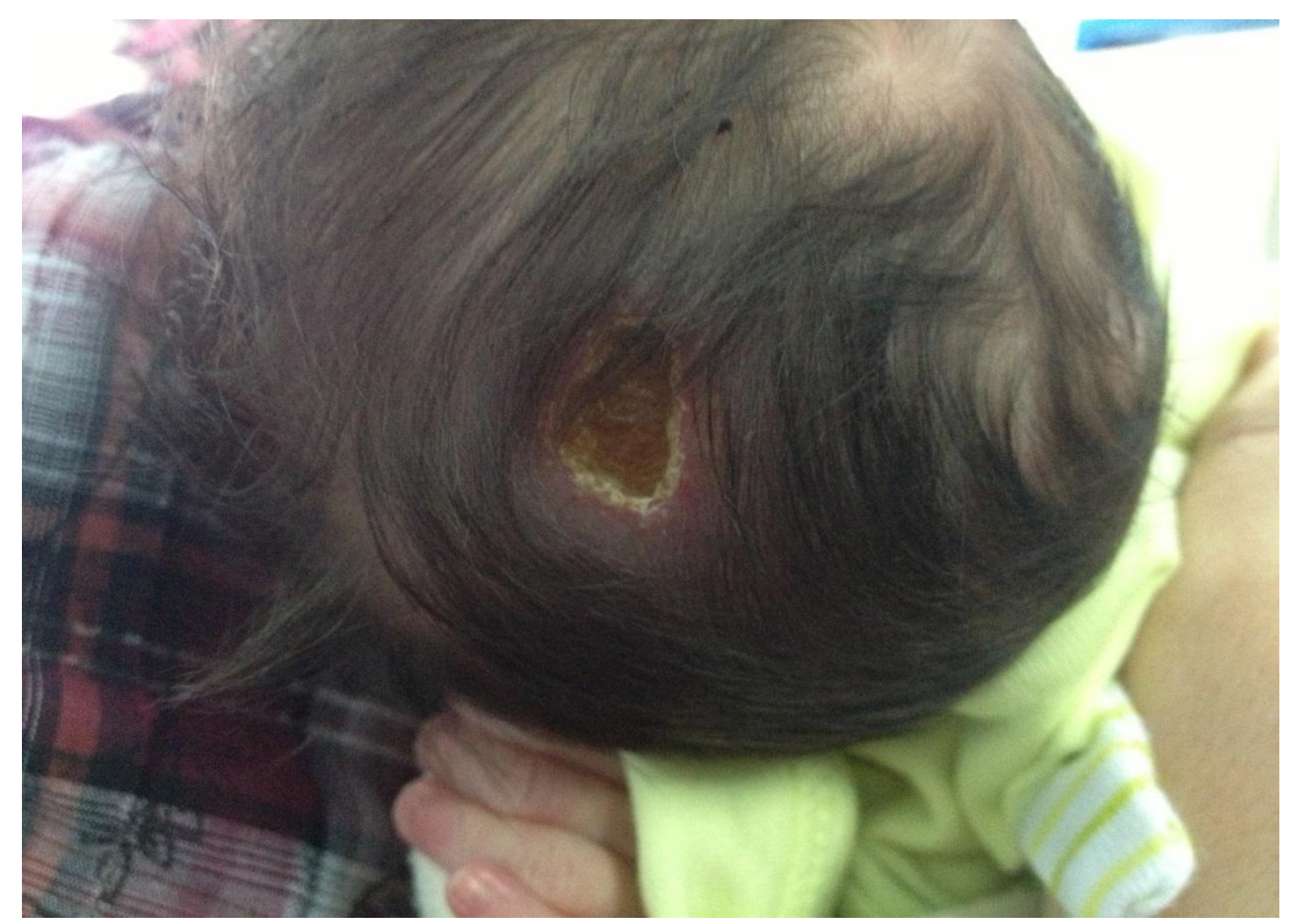

Resim 2. Sol parietooksipital alanda cilt defekti izlenmektedir. 


\section{Tartışma}

Aplazia kutis konjenita cilt defektiyle giden ve oldukça nadir görülen bir sendromdur. Frieden hastalığ 1 lezyonun sayıs1, lokalizasyonu ve malformasyon eşlik edip etmemesine göre 9 grupta sınıflandırmıştır (4) (Tablo I).

Tablo 1

Frieden Sinıflaması

\begin{tabular}{|l|l|}
\hline 1 & Eşlik eden anomalinin olmadığ AKK \\
\hline 2 & Ekstremite anomalileri ile beraber AKK \\
\hline 3 & Epidermal veya orgonoid nevüslerle birlikte AKK \\
\hline 4 & Embriyonik malformasyon üzerinde AKK \\
\hline 5 & 'Fetus papareseus' veya plasenta enfaktlar ile birlikte AKK \\
\hline 6 & Epidemolisis büllosa ile birlikte AKK \\
\hline 7 & Ekstremitede büllerin eşlik etmediği AKK \\
\hline 8 & Teratojenlerle ilişkili AKK \\
\hline 9 & Malformasyon sendromları ile birlikte AKK \\
\hline
\end{tabular}

Grup 1 multipl anomalinin eşlik etmediği sıklıkla skalpde izole cilt defekti varlığıla giden otozomal dominant ya da sporadik görülebilen lezyonlardır. Grup 2 cilt defektine ekstremite anomalisinin de eşlik ettiği Adam's Oliver sendromunu kapsayan gruptur. Grup 3 epidermal, sebase nevüslerin de eşlik ettiği hastalardır. Nevüs sıklıkla aplasia ile komşu alan içindedir. Konvülziyon, mental retardasyon, iris kolobomu gibi nörolojik bulgular ve göz bulguları eşlik edebilir. Grup 4 Aplazia kutis konjenita üzerine eklenmiş meningomiyelosel, gastroşisiz, omfalosel gibi embriyolojik malformasyonların olduğu gruptur. Grup 5 aplasia kutis konjenita fetus papyraceous veya plasental infakt ile birliktedir. Özellikle gövdede ya da ekstremitede var olan lineer veya satellit konfigürasyondaki aplazia kutis fetus papayraceous ile ilişkilidir. Grup 6'da aplazia kutis epidermolisis bülloza ile birlikte görülür. Lezyon sıklıkla alt ekstremitededir. Pilorik, duodenal atrezi, üretral stenoz renal anomaliler eşlik edebilir. Grup 7'de ise epidermolisis büllosanın olmadığı alt ekstremite yerleşimli aplazia kutis konjenita olguları vardır. Grup 8'de neden teratojenlerdir. Gebelikte herpes simpleks, varisella enfeksiyonu veya metimazol kullanımı teratojenlere örnektir. Grup 9'da ise aplazia kutisin sendromlarla birlikte görüldüğü vakaları içerir. Su ana kadar bildirilenler arasinda Wolf Hirschhorn, Trizomi 13, Goltz Sendromu, Ellis-van Creveld Sendromu, Barts sendromu vardır. Siklıkla tek izole defekt olmakla birlikte multipl lezyonlarda saptanabilir. Saçlı deri, hastalığın en sık görüldüğü bölgedir. Vakaların \%70'ini kapsar $(5,7)$. Deri defektine ekstremite, göz, genitoüriner sistem, gastrointestinal sistem, santral sinir sistemi anomalileri eşlik edebilir (8). Hastalarımızda lezyonlar saçlı deri yerleşimliydi ve ek anomali eşlik etmiyordu. Frieden 
sinıflamasına göre grup 1'e girmekteydi. Vakaların \%20-30'unda alttaki kemik doku ve dura mater de etkilenebilir (9). İkinci s1klıkta alt ve üst ekstremiteler etkilenir (10). Lezyonlar doğumda inflamasyonun eşlik etmediği parlak kırmızı zeminde ülsere, egzamatöz veya atrofik, iyi sınırlı alanlardır ve büyüklügü değişkendir (8). Etkilenen bölge tipik olarak ince şeffaf bir membranla kaplıdır. Yerini 1-3 ay içinde periferden santrale doğru düz kağıt gibi ince saçcız bir alana bırakır. Özellikle cilt altı dokuların da etkilendiği ağır vakalarda masif hemoraji, enfeksiyon, menenjit gibi hayatı tehdit eden komplikasyonlar görülebilir (6). Patofizyolojisi tam bilinmemekle birlikte embriyonik dönemde kokain, eroin, alkol veya antitiroid ilaç maruziyeti gibi teratojen maruziyeti sonucu epidermal ve organ gelișiminin duraksaması veya intrauterin dönemde plasental infakt, tek arter nedenli dolaşım bozukluğu, intrauterin travma, amniyotik band üzerinde durulmaktadır (8). Plasenta incelemesi enfakt alanlarının gösterilmesi ile tanıya yardımcı olabilir (11). Moya moya hastalığı ile birlikteliği rapor edilmiştir (12). Epidermolisis büllosa veya Herpes simpleks virüsü, Varisella zoster virüsü gibi intrauterin enfeksiyonlarla ilișkili olabilir. Ancak literatürde sunulan vakaların çoğunda altta yatan neden tanımlanamamıştır $(13,14)$. Olgularımızda da prenatal dönemde annede döküntülü hastalık ya da ilaç kullanımı öyküsü yoktu. Bebeklerin fizik muayenesinde genitoüriner, gastrointestinal ve santral sinir sistemleri dahil ek anomali saptanmadi. Aplazia kutis konjenitaya zemin hazırlayıcı herhangi bir risk faktörü tanımlanmadı. Düzensiz otozomal dominant kalıtım gösteren birçok ailesel olgu, daha nadir olarak da otozomal resesif kalitım gösteren olgular bildirilmiștir (15). Ancak bu olgularda akraba evliliği yoktu. Hastalığın tanısında spesifik bir laboratuar testi yoktur. Bu nedenle lezyonların bilinmesi klinik tanı için çok önemlidir. Özellikle cilt defekti büyük ve birden fazla alanı etkileyen vakalarda hayatı tehdit eden olası menenjit, kanamayı önlemek ve açıkta kalan beyin dokusunu travmalara karş1 korumak gerekir. $\mathrm{Bu}$ vakalarda görüntüleme yöntemi ile alttaki kemik ve dokunun da değerlendirilmesi gerekir (16). Vakalarımızın çekilen kranial görüntülemelerinde kemik doku bütünlüğü korunmuştu. İzole lezyonlar tipik olarak haftalar içerisinde kendiliğinden geride atrofik saçsız alan bırakarak iyileşir. Eşlik eden küçük kemik defekleri de bir sene içinde kendiliğinden kapanır. Hastalarımızda aktif dönemde lezyonun kuruması önlenerek için yumuşak parafin ile doyurulmuş, \%5 oranında klorheksidin asetat içeren delikli gazlı bez ile bakım yapıldı (16). Ek anomali tanımlanmayan, genel durumu iyi, oral alabilen bebekler poliklinik kontrolü ile izleme alındı. Lezyonların zaman içinde atrofik zeminde saçsız alan olarak sebat ettiği gözlendi. Aplasia Kutis Konjenita nadir görülen bir anomali olmakla birlikte, eşlik eden anomalilerin olması, çeşitli sendromlarla birlikteliği, genetik geçişli olabilmesi ve lezyonun geniş olduğu vakalarda hayatı tehdit eden komplikasyonların varlığı nedeniyle önemli bir hastalıktır. Tanısı için spesifik bir laboratuvar testi olmayan AKK'da klinik tanının ve değerlendirmenin önemine dikkat çekilmiştir. 


\section{KAYNAKLAR}

1. Bajpai, M. Pal, K. (2003). Aplasia cutis cerebri with partial acrania total reconstruction in a severe case and review of the literature. $J$ Pediatr Surg.38(2): e4.

2. Campbell, W. (1826). Case of a congenital ulcer on the cranium of fetus terminating in $\mathrm{f}$ a $\mathrm{t}$ a 1 haemorrhage on the 18th day after birth. J Med Sci. 2, 82.

3. Adams, F. H. Oliver, C.P. (1945). Hereditary deformities in man due to arrested development.J Hered.36,3-10.

4. Frieden, I.J. (1986). Aplasia cutis congenita: a clinical review and proposal for classification. J Am Acad Dermatol. 14(4), 646-660.

5. Moriya, J. Kakeda, S. Korogi, Y. (2006). An unusual case of split cord malformation. Am J Neuroradiol. 27, 1562-1564.

6. Burkhead, A. Poindexter, G. Morrella, D.S. (2009). Case of extensive Aplasia Cutis Congenita with underlying skull defect and central nervous system malformation: discussion of large skin defects, complications, treatment and outcome. J Perinatol. 29, 582-585.

7. Verhelle, N.A. Heymans, O. Deleuze, J.P. (2004). Abdominal studies in the pathology and development. Am aplasia cutis congenita: case report and review of the literature. $J$ Pediatr Surg, 39, 237-239.

8. Gazioglu, N. Abuzayed, B. Aslan, H. (2012). Repair of the venous sinus defect with bovine pericardium dura substitute in a case aplasia cutis congenita. Neurosurg Quart,22,19-21.

9. Elliott, A.M. Teebi, A.S. (1997). Further examples of autosomal dominant transmission of nonsyndromic aplasia cutis congenita. Am. J. Med. Genet, 73, 495-496.

10. Croce, E.J. Purohit, R.C. Janovski, N.A. (1973). Congenital absence of skin (Aplasia cutis congenita). Arch Surg, 106, 732.

11. Chitnis, M.R. Karachi, R. Galea, P. (1996) Familial aplasia cutis congenita. Eur. J. Pediatr Surg, 6,100.

12. Glasson, D.W. Duncan, G.M. (1985). Aplasia cutis congenita of the scalp: delayed closure complicated by massive hemorrhage. Reconstr Surg, 75,423 .

13. Kruk-Jeromin, J. Janik, J. Rykala, J. (1998). Aplasia cutis congenita of the scalp. Report of 16 cases. Dermatol Surg, 24, 549-553.

14. Moros, P.M. Labay, M.M. Valle, S.F. (2000). Aplasia cutis congenita in a newborn: Etiopathogenic review and diagnostic approach. An Esp Pediatr, 52, 453-456.

15. Dallapoiccola, B. Giannotti, A. Marino, B. (1992). Familial aplasia cutis congenita and coarctation of the aorta. Am J Med Genet, 43, 762.

16. Levine, S.M. Reformat, D.D. Thorne, C.H. (2012). Cutis Aplasia: Perioperative Management and Case Report Am J Crit Care, 21, 212-215. 